"W" is a Nicols prism will be apt to confuse the student. The resistance pyrometer is said to give the correct temperature to a tenth of a degree at $1000^{\circ}$ $\mathrm{C}$, but owing to the coating required to protect the platinum wire for most work, nothing like this accuracy will be obtained in practice. In speaking of the useful Féry spiral pyrometer, it is indicated that one of its objections is that it will only give "black body" temperatures, but surely this limitation applies to the other radiation pyrometers also.

The account of the manufacture of Sheffield steelmelting crucibles is not correct, nor is the statement (p. 346) that the crucible is "put to dry, after which it is used without firing," as these crucibles are subjected to a very careful firing, or annealing, on a very ingeniously designed annealing grate. Also, amongst the addition of non-plastic material added to enable the crucible to be made without cracking, are mentioned burnt clay, silica, and graphite; but in Sheffield work the material used is the best ground coke-dust, which not only has this effect, but by forming a solid skeleton to the material of the crucible at temperatures at which the fireclay material is quite soft, enables the crucible to stand the necessarily rough usage to which it is subjected during the making of crucible steel, without losing its shape. If from any little accident in the annealing of the crucible air has been allowed to impinge on any part of it so as to burn out the coke-dust, the crucible loses its shape at these portions, and is exceedingly difficult to manipulate.

The whole subject-matter of the book covers a very wide field, and these critical observations are not intended to indicate that the work will not be a useful one for students, but are only intended to set them on their guard in cases where it will be necessary for them to know the exact state of practical work, or to compare with other authorities where their own experience seems to differ from the statements made in the book.

A. McWilliam.

\section{MEDICAL PARASITOLOGY.}

A Handbook of Practical Parasitology. By Prof. Max Braun and Dr. M. Lühe. Translated by Linda Forster. Pp. viii +208 . (London: J. Bale, Sons and Danielsson, Ltd., I9Io.) Price Ios. 6d. net.

THIS is a handy and very useful work by two ex1 tremely competent authorities, and well worth translating into English for the benefit of medical men and others to whom the German language may present difficulties. The book is divided into three parts-(i.) Protozoa, (ii.) Helminthes, and (iii.) Arthropoda. Each of these sections begins with an introductory portion, in which, after a general account of the group, very full directions are given for its practical study, with an excellent summary of the most important and useful methods of technique. The group is then dealt with systematically, those forms most important for the purposes of the book being described in their place in the classification, and for each main subdivision a common and easily obtained type is described in detail with directions for procur- ing and studying it. The information given is in general accurate and up-to-date-the date, that is to say, of the German edition-and the figures are clear and well executed.

In the Protozoa the step is taken of abolishing the class Sporozoa and elevating its two principal subdivisions, Neosporidia and Telosporidia, to the rank of independent classes. The Neosporidia are placed immediately after the Rhizopoda, while the Telosporidia follow the Flagellata, but with subtraction of the Hæmosporidia, which are classified with the Trypanosomidæ amongst the Flagellata as the third order, Binucleata, of that class. In their treatment of these organisms the authors take up an advanced neoSchaudinnian standpoint with regard to certain highly controversial questions.

The term Helminthes has no zoological significance, but is used in a sense convenient for medical requirements to comprise the Trematodes, Cestodes, Nematodes, and Acanthocephala; not, however, the leeches. In the section Arthropoda, which is a brief one, an account is given of the mites, Linguatulids, lice, fleas, and parasitic Diptera. The Arthropods which transmit parasites, such as ticks and "stinging-flies" (sic), are dealt with under the Protozoa.

The translation is, in general, clear, but some curious results arise from the translator's desire to anglicise scientific terms. It appears to be a rule with her to convert the termination "-idium," plural "-idia," into "-ide," plural "-ides," and the consequences are in many cases very puzzling. "Coccide," for instance, suggests a cochineal insect, but means in this book a coccidian parasite. No zoologist would ever guess the meaning of "Myxides," used to denote individuals of the common parasite of the bladder of the pike, Myxidium lieberkühni. Most zoologists, and many people who are not zoologists, are familiar with chromidia, disguised here as "chromides." In these and many other cases the meaning of the term used can only be inferred from the context or deduced from analogy. It is also very misleading to use the term "carnivori" to denote birds of prey (p. 60); "smallpox" on p. 32 should be carp-pox; and Trypanosoma, in the description of Fig. I4, should be Trypanoplasma. It is to be regretted that the eminent zoologists and others, to whom the translator expresses her indebtedness for assistance, did not correct these vagaries.

E. A. M.

\section{POPULAR ASTRONOMY.}

(1) Astronomy, a Handy Manual for Students and Others. By Prof. F. W. Dyson, F.R.S. Pp. vii + 247. (London: J. M. Dent and Sons, Ltd., 1910.) Price 2s. 6d. net.

(2) Chats about Astronomy. By H. P. Hollis. Pp. vi +226. (London: T. Werner Laurie, n.d.) Price 3s. $6 d$. net.

ANY signs point to the fact that the popular i 1 interest in astronomy grows from day to day. Perhaps in revolt against the merely utilitarian the world will not willingly let die the least obviously practical of the sciences. The production of books,

NO. 2 I 35 , VOL. 84] 